\title{
Strategy Visualization, Cognitive Frames, and Strategy Renewal in SMEs
}

\author{
Marco Vedovato \\ Ca' Foscari University, Venice, Italy
}

\begin{abstract}
This paper provides experimental evidence that visual representation of strategy and related concepts increases the probability of updating the cognitive frames of small entrepreneurs. An original strategy mapping technique and Osterwalder and Pigneur's (2010) business model canvas were used to help 42 small entrepreneurs to critically review their current strategies and choices. A questionnaire about perceptions of the external environment and internal structure was submitted to the participants before and after the experiment. The same questionnaire was submitted twice to a matched control group of $50 \mathrm{SME}$ entrepreneurs who were not involved in any activity. The results show that involvement in the visualization experiment significantly increased the probability of the participant changing perceptions on strategic issues, with a stronger impact for strategy mapping. The results are interpreted as indicative of a positive contribution of visual representation in strategy renewal.
\end{abstract}

Paper type: Research paper

Keywords: Strategy Visualization, Strategy Map, Business Model Canvas, Experiment, Small and Medium-size Enterprises, Strategy Renewal 


\section{Introduction}

The identification of methods supporting strategic renewal has gained increasing attention as many businesses struggle to keep pace with increasing global competition. Strategy renewal is, at best, difficult to achieve. Technical innovations, regulatory changes, and market crises require adaptations to existing strategies and business models and, while some firms are able to adapt, many are subject to strong inertial forces (Kaplan, 2008). Research in managerial cognition suggests that the problem may lie in the cognitive process of noticing and interpreting environmental changes (Barr et al., 1992). Especially in periods of high uncertainty, cognitive frames are crucial in interpreting ambiguous signals and thus in strategic choices (Walsh, 1995). Keeping cognitive frames up-to-date is therefore a critical task, because relying on unsuitable mental models will result in inadequate responses to the environment.

Unfortunately, updating cognitive frames is not easy. Inertial forces delay the updating process and very often only extremely strong signals are able to force change. There is, therefore, a clear need for tools and methodologies capable of facilitating changes to cognitive frames to help decision makers update their interpretation of a firm's situation before it deteriorates. Mezias et al. (2001) identify facilitated strategic workshops as a means of challenging existing beliefs and then enabling the development of new, fresher mental models. Similar advantages are attributed to visual representations. According to Eppler and Platts (2009), visualization can enable the reframing of current views, foster changes in perspectives, and facilitate the systematic and global comparison of many options.

Visualization tools are certainly not new in strategy and management. Strategy analysis classics such as Porter's (1980) five forces, the Boston Consulting Group matrix (Henderson, 1979), and strategic group maps (McGee and Thomas, 1986) all encompass important visual characteristics. More to the point of this paper are strategy maps. Made popular by Kaplan and Norton $(2000,2004,2006)$ especially as a strategy implementation tools, strategy maps have an older tradition (Eden, 1988; Huff, 1990; Fiol and Huff, 1992) and can serve also for supporting strategy development. Strategy maps are a visual representation of strategy and related issues. They help investigate a strategic problem by facilitating the simultaneous consideration of many relevant variables, supporting the identification of causal relations among them (Cheng and Humphreys, 2012), and helping make tacit assumptions explicit. Strategy maps can also guide decision makers, providing a simplified model of the strategic domain that is useful in anticipating decisions and foreseeing consequences (Csaszar and Levinthal, 2015).

The business model canvas is another tool for the visual representation of strategyrelated issues that has gained wide popularity over the last decade (Osterwalder, 2004; Osterwalder and Pigneur, 2010). It is a simplified scheme for representing and projecting business models and identifying new strategic alternatives. It aims to provide a general model to easily describe and manipulate business models in organizations of all kinds, including large corporations, non-profits, and new ventures. It has also become a very common tool in the development of start-up business plans (Trimi and Berbegal-Mirabent, 2012). 
Business models and strategy are distinct but connected concepts (Teece, 2010). A business model articulates the logic of value creation for customers, how the firm can be organized to best meet its customers' needs, get paid, and make a profit. Strategy defines strategic objectives in light of environmental characteristics and available resources and delineates the initiatives and policies necessary to obtain a sustainable competitive position. The preparation of both strategy maps and a business model canvas imply critical reasoning that is capable of producing modifications in cognitive frames. Developing a business model canvas requires making assumptions about customers, the changing nature of their needs, critical processes and resources, and possibly competitor responses. Developing a strategy map requires the critical consideration of environmental constraints and available resources to identify objectives and the policies to achieve them.

This paper aims to evaluate the effectiveness of strategy maps and the business model canvas as tools to support the updating of cognitive frames and thus strategic renewal. Despite the widespread diffusion in the business environment of strategy maps and business model canvas, little empirical research has been conducted to evaluate their claimed benefits. One exception is the study by Cheng and Humphreys (2012), which examined by means of a laboratory experiment the effect of the strategy map on the ability to interpret the strategic relevance of external information and on the use of this information to evaluate the organization strategy. Our study, however, marks something of a departure from this literature as we rely on a field experiment and focus on the possible role of visualization in promoting the challenging of consolidated beliefs and the renewal of cognitive frames through which external information is interpreted.

Therefore, our contribution the literature can be summarized as follow. First we extend the still limited empirical research on the impact of strategy mapping and provide possibly the first evidences on the actual impact of the Business Model Canvas. Second, we contribute to the literature on methods for promoting strategic renewal (Simons, 1994; Doz and Kosonen, 2010), as we show that the visual representation of strategy and related issues can be beneficial for the updating of cognitive frames and the strategic interpretation of environmental information.

\section{Research Method}

\subsection{Data sources and research design}

SME support projects promoted by the SME Associations of Veneto, Italy, offered the opportunity for the study. Such SME representative associations offer representation and services to small business owners. It is therefore part of their mission to engage with entrepreneurs in activities aimed at supporting their competitive strength. From 2010 to 2015 , a number of initiatives offered small entrepreneurs the opportunity to participate to strategy check-up sessions.

To assess the differential effect of the visual representations, a control group of 80 SMEs was selected among members of the aforementioned associations. They were asked to complete the same questionnaire as the experimental group. They were then

International Journal of Management and Applied Research, 2016, Vol. 3, No. 1 
contacted by phone after 10-15 days and administered the questionnaire again, without reference to the first round (see Figure 1).

Figure 1: Experiment Design

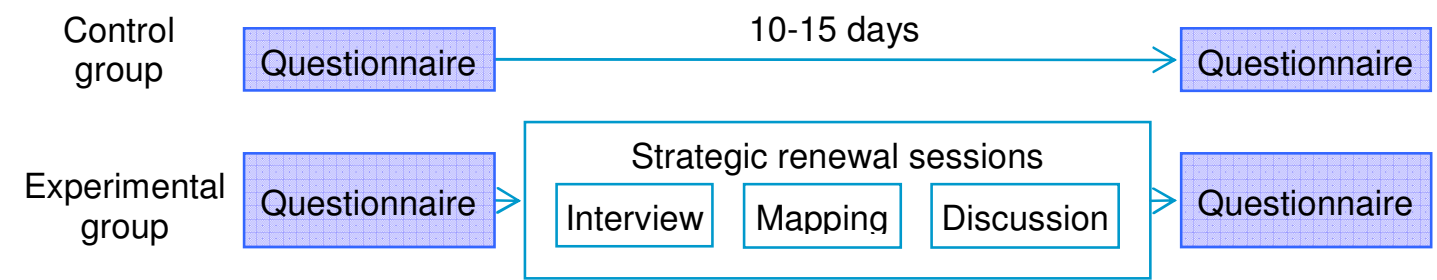

A total of 44 entrepreneurs were involved in the experimental group. The entrepreneurs in the experimental group were invited to participate in a series of activities supporting strategic renewal, which were guided by experienced business analysts. The sessions consisted of the following: 1) semi-structured interview; 2) preparation of a visual representation (either a strategy map or a business model canvas) of what emerged during the interviews, and 3) a concluding examination of the critical issues. For research purposes, before starting the interview and after discussing the maps, the entrepreneurs were asked to complete a short questionnaire designed to express their evaluation of a number of strategic issues, including their attitudes about sector perspectives, their companies' perceived relative strengths, and the adequacy of available resources (see Annex 1).

Since the research design requires the questionnaire to be completed twice, we had to drop cases that were missing the second questionnaire. Usable data were obtained from 42 entrepreneurs in the experimental group and 50 in the control group (see Table 1). The study participants shared key demographics: They were in their 40s (mean age 48 years, standard deviation six years), mainly male (83\%), and, generally, with limited formal training but technical skills acquired on the job.

Table 1: Comparison the experimental and control groups

\begin{tabular}{|l|l|r|r|}
\hline \multicolumn{2}{|c|}{} & $\begin{array}{r}\text { Experimental group } \\
\text { percentage }\end{array}$ & $\begin{array}{r}\text { Control group } \\
\text { percentage }\end{array}$ \\
\hline \multirow{3}{*}{ Type of business entity } & Sole proprietorship & $26 \%$ & $30 \%$ \\
\cline { 2 - 4 } & Partnership & $36 \%$ & $32 \%$ \\
\cline { 2 - 4 } & Limited Company & $38 \%$ & $38 \%$ \\
\hline \multirow{5}{*}{ Net sales (€'000) } & Up to 200 & $45 \%$ & $44 \%$ \\
\cline { 2 - 4 } & From 200 to 1000 & $29 \%$ & $34 \%$ \\
\cline { 2 - 4 } & From 1000 to 5000 & $21 \%$ & $22 \%$ \\
\cline { 2 - 4 } & More than 5000 & $5 \%$ & $0 \%$ \\
\hline Industry sector & Up to 4 & $62 \%$ & $60 \%$ \\
\cline { 2 - 4 } & From 5 to 10 & $21 \%$ & $18 \%$ \\
\cline { 2 - 4 } & From 11 to 50 & $14 \%$ & $22 \%$ \\
\cline { 2 - 4 } & More than 50 & $2 \%$ & $0 \%$ \\
\hline & Construction & $38 \%$ & $42 \%$ \\
\cline { 2 - 4 } & Wood and furniture & $29 \%$ & $34 \%$ \\
\cline { 2 - 4 } & Mechanical & $21 \%$ & $20 \%$ \\
\cline { 2 - 4 } & Services & $12 \%$ & $4 \%$ \\
\hline
\end{tabular}

Note: This table compares the experimental and control groups. To show that the business owners in the experimental and control groups manage comparable firms, the table compares the proportions of businesses by type of entity, net sales, number of employees, and industry sector.

International Journal of Management and Applied Research, 2016, Vol. 3, No. 1 


\subsection{Experiment 1: Strategy mapping}

The first method used on the experimental group consists of a visual representation of business strategy (see Figure 2). It shares with Kaplan and Norton's strategy maps the aim of visually represents the cause-and-effect relationships among the components of an organization's strategy, but departs from them, as it requires to explicitly link strategic objectives to relevant internal and external variables. More specifically business strategy is described as the linking of six elements: the external environment, internal structure, strategic objectives, external policies, internal policies, and activities. The external environment and internal structure describe the boundaries and positive forces affecting the strategy. They are, at least implicitly, the determinants of the strategic objectives; that is, the selected strategic objectives are influenced by the entrepreneur's perceptions of the external environment and internal structure and their expected positive and negative impacts. Strategic objectives, in turn, have to be translated into policies or projects, which will be labeled as external if aimed at affecting the firm's environmental position and as internal if aimed at influencing its internal structure. Finally, both external and internal policies will affect activities, since they require changes to everyday processes.

The construction of the strategy map involves two steps. First, the most relevant issues for each element are identified and, second, they are linked to other elements to make explicit interdependencies and causalities.

Figure 2: Strategy map template

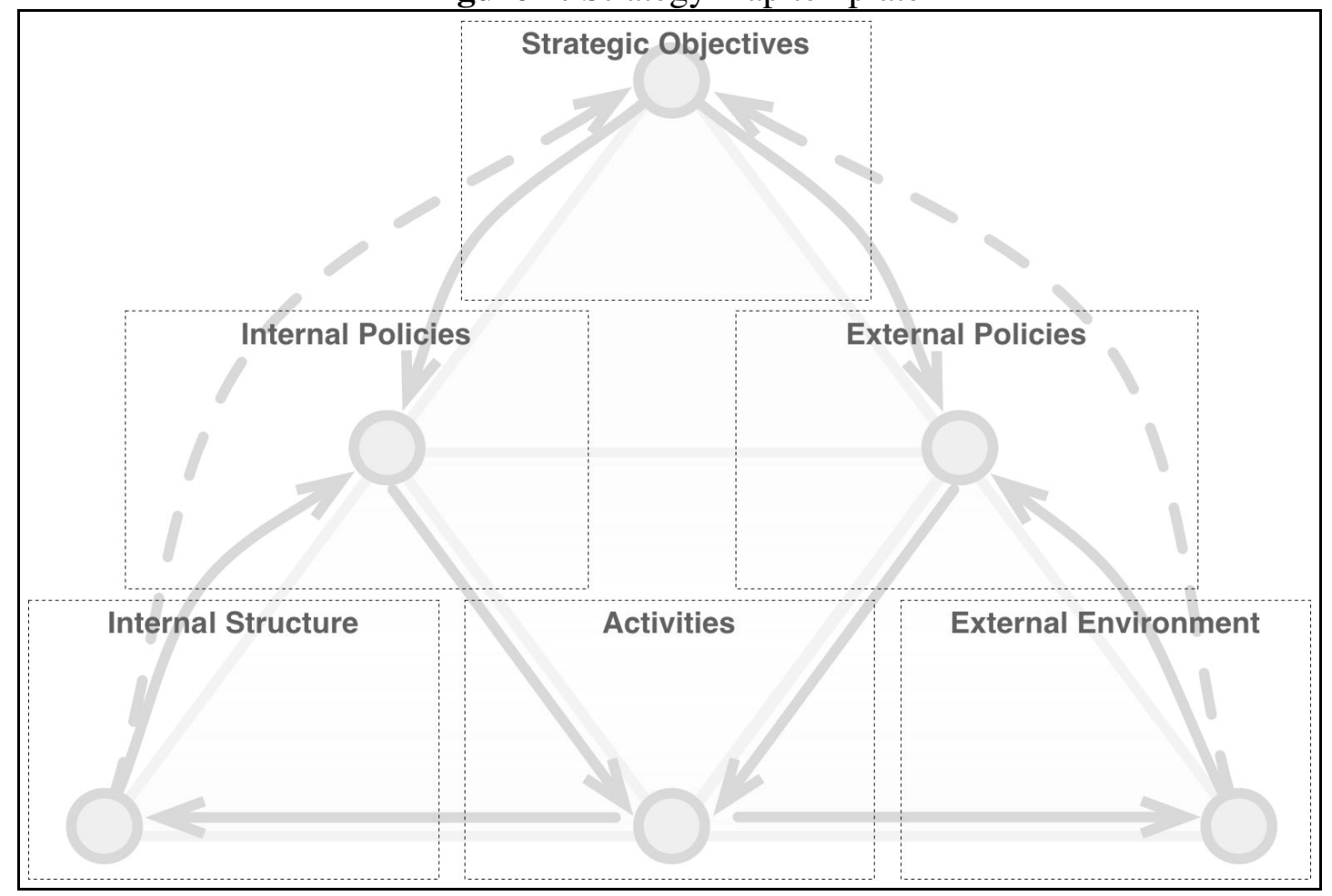

Note: The strategy map links six elements relevant for the representation of one business strategy. The template requires explicitly linking strategic objectives with both internal structure and the external environment, inducing a critical consideration about the internal and external variables relations and their coherence with selected objectives. Strategic objectives need to be implemented through policies, which in turn require changes to everyday activities. The strategy map aims at inducing a critical reflection on the six elements coherence. 
The identification phase is based on an in-depth semi-structured interview, during which the entrepreneur is shown the map template (see Figure 2). The analyst explains to the entrepreneur the rationale of the map and then start asking general questions related to each element. For example, regarding the external environment, a typical starting point for discussion, the standard starting question is, "What are the main features of the external environment one should know to understand what your business is facing?" Depending on the answer, other questions can then be posed to clarify the aforementioned issues or to check if some important point has been omitted.

Once all six elements of the map have been discussed and the most relevant issues identified, the linking phase can begin, in which the analyst asks the entrepreneur how the identified issues connect. For example, taking a strategic objective as a starting point, the analyst could ask, "You mentioned objective x. What elements of the external environment lead you to believe this is feasible? And what are the main obstacles you see?" The questions are aimed at both identifying interdependencies and causalities between issues and verifying if the picture that emerged in the identification phase requires adjustment. For instance, missing issues could be added if a new explanation emerges, while others could be deleted if they no longer seem relevant in the general picture. The interview process took two to four hours overall, depending on the complexity of the organization. Of course, it was left to the analyst to fine-tune the interview process to consider firm specificity. For instance, if the organization was very small, discussion about its internal structure was directed toward the perceived relative strength of the entrepreneur's skills, the quality of human resources, and the perceived adequacy of the available tools and instruments.

Once the interview is concluded, the analyst reviews the collected material and prepares the map using an add-on for commercial business graphics software. In a following session, the analyst shows the map to the entrepreneur, highlighting the issues identified and explaining interdependencies and causal relations. The analyst then asks the entrepreneur if the overall picture correctly represents his or her thoughts. If not, the required changes are made to the map. Then, the analyst concludes the experiment, briefly commenting on the strategy map, highlighting the coherence among the issues and the most critical points (e.g., probable sources of difficulties).

\subsection{Experiment 2: Business model canvas}

The business model canvas (Osterwalder and Pigneur, 2010) is a tool aimed at facilitating the description and manipulation of business models to create new strategic alternatives. It offers a simplified visual scheme that encompasses the relevant concepts and their relations in understanding business logic. The business model canvas is structured as nine building blocks: customer segments, value proposition, channels, customer relationships, revenue streams, key resources, key activities, key partnerships, and cost structure. Each building block can be described by one or more concepts, which can be defined with the help of a set of questions. The sketching of the business model is intended to support the discussion and 
ultimately help challenge assumptions and identify innovative and effective ideas, for both the launch of new businesses and the transformation of existing outmoded ones.

In this study, the business model canvas was used in the experiment as follows. First, the tool's rationale was explained to the participants. Then, each building block was discussed to describe the actual state of the business. Attention then shifted to environmental novelties and the challenges they pose to the existing business model. Finally, intended changes to the business model were outlined and the resulting picture discussed, particularly its feasibility and competitive sustainability. Overall, the interview process took about three hours.

\section{Results}

The main goal of the experiment was to investigate if visual tools for representing strategy and related concepts have a significant impact on entrepreneurs' perceptions of strategic variables. More specifically we are interested in observing the shifts in respondents opinions occurred from the first to the second administration of the questionnaire. To this end we compute the difference in the absolute values of the answers for each individual respondent:

$$
\text { Difference }_{i}=\mid \text { First answer }_{i}-\text { Second }_{\text {answer }} \mid
$$

Table 2 reports the mean values of Difference for the aforementioned groups. The entrepreneurs involved in sessions regarding a visual representation of strategy and related concepts (the experimental group) changed their answers more than those in the control group for all the questions. The difference is significant for questions dealing with the firm's future prospects, the evaluation of available resources, the firm's current prospects, the expected future of the industry, and the evaluation of product attractiveness, although the last two differences are significant only at the $10 \%$ level.

Table 2: Changes in answers: experimental and control group

\begin{tabular}{lccc}
\hline & $\begin{array}{c}\text { Experimental } \\
\text { group }\end{array}$ & Control group & $\begin{array}{c}\text { Difference test between } \\
\text { experiment and control }\end{array}$ \\
\hline $\begin{array}{l}\text { Current industry } \\
\text { prospects }\end{array}$ & 0.38 & 0.28 & 0.10 \\
$\begin{array}{l}\text { Future industry } \\
\text { prospects }\end{array}$ & 0.45 & 0.24 & $0.21^{*}$ \\
$\begin{array}{l}\text { Current firm prospects } \\
\text { Future firm prospects }\end{array}$ & 0.69 & 0.40 & $0.29^{* *}$ \\
Strength relative to & 0.86 & 0.24 & $0.62^{* * *}$ \\
competitors & 0.40 & 0.36 & 0.04 \\
Product attractiveness & 0.52 & 0.32 & $0.20^{*}$ \\
Resources & 0.74 & 0.36 & $0.38^{* * *}$ \\
\hline
\end{tabular}

Note: This table reports the mean changes in the entrepreneurs' answers between the first and second rounds of the questionnaire. Entrepreneurs in the experimental group changed their answers significantly more than those in the control group did. The significance of the difference between groups is tested with a Wilcoxon test. *** $\mathrm{p}<0.01, * * \mathrm{p}<0.05, * \mathrm{p}<0.1$. 
As for the differential impact of the two experimented methods (see Table 3), the strategy map had a slightly stronger impact than the business model canvas did. The difference between the two methods is statistically significant for questions about the firm's future prospects and the industry's future prospects, but only at the $10 \%$ level.

Table 3: Changes in answers; strategy map and business model canvas group

\begin{tabular}{|c|c|c|c|}
\hline & $\begin{array}{l}\text { Strategy map } \\
\text { group }\end{array}$ & $\begin{array}{l}\text { Business model } \\
\text { canvas group }\end{array}$ & $\begin{array}{l}\text { Difference test between } \\
\text { strategy map and business } \\
\text { model canvas }\end{array}$ \\
\hline \multicolumn{4}{|l|}{ Current industry } \\
\hline \multicolumn{4}{|l|}{ Future industry } \\
\hline prospects & 0.53 & 0.20 & $0.33^{*}$ \\
\hline Current firm prospects & 0.72 & 0.60 & 0.12 \\
\hline Future firm prospects & 0.94 & 0.60 & $0.34 *$ \\
\hline \multicolumn{4}{|l|}{ Strength relative to } \\
\hline Product attractiveness & 0.53 & 0.50 & 0.03 \\
\hline Resources & 0.75 & 0.70 & 0.05 \\
\hline \multicolumn{4}{|c|}{$\begin{array}{l}\text { Note: This table reports the mean changes in the entrepreneurs' answers between the first and second } \\
\text { rounds of the questionnaire. Entrepreneurs in the strategy map group changed their answers slightly } \\
\text { more than the business model canvas group did. The significance of the difference between groups is } \\
\text { tested with a Wilcoxon test. *** } p<0.01, * * p<0.05, * p<0.1 \text {. }\end{array}$} \\
\hline
\end{tabular}

\section{Discussion}

The results of this study suggest the effectiveness of strategy visualization in promoting critical reflection on strategic issues and modifying entrepreneurs' perceptions. The entrepreneurs involved in the intervention significantly changed their evaluations of important strategic variables. Building on the well-established principle in cognitive science that cognition mediates the relation between the environment and the organizational response, we argue that the changes in evaluations we report could be indicative of an updated strategic approach.

A stronger impact was obtained in the evaluation of future business prospects. Interestingly, this was also the question for which the two experimented methods differed the most. A significant impact was also determined in the evaluation of available resources and current firm prospects. In view of the fact that, altogether, these three issues are indicative of entrepreneurs' attitudes toward their business and their confidence regarding it, we argue that strategy mapping is effective in challenging entrepreneurs' beliefs about their firms' strengths and weaknesses. However, beliefs more closely related to the external environment were less affected. Evaluation of the relative strength of competitors was among the few variables not affected, along with current industry perspectives, a dimension that is probably beyond entrepreneurial efforts. We argue that these results are indicative of the capacity of visual representations to induce critical reflection of existing choices and to challenge their evaluation. This can lead to a revision of expectations about the future, a promising first step toward strategic renovation. 
Overall these results are consistent with those of Cheng and Humphreys (2012), who find that strategy maps confer significant benefits to strategic judgments, thanks to the explication of casual linkages between objectives.

The two tools used in the study for the visual representation of strategy produced slightly different results. The business model canvas was marginally less effective at inducing changes in the perceptions of all the strategic variables. However, these differences are only statistically significant for two issues and only at the $10 \%$ level. With this limitation in mind, it is worth observing that the only two questions with a significant difference were related to expectations for the future, that of the firm and that of the industry. This may not come as a surprise, since the business model canvas lacks an explicit connection to environmental variables and may thus be less effective at inducing critical reflection of the external consequences of internal choices or of the internal impact of external changes. The strategy map, on the contrary, requires explicitly linking strategic objectives with both internal structure and the external environment, leading to a comprehensive assessment of the internal and external variable relations.

Moreover, it's worth observing that the business model canvas encourages static representations of the business problem since it does not require pointing out future projects or policies. This may not be an issue when developing a new venture business model, but is possibly a limitation for supporting strategy renewal of established businesses. The strategy map, on opposite, entails the translation of strategic objectives into policies or projects, suggesting that an ensuing action is needed.

Overall, one can hypothesize that the business model canvas is relatively less effective at inducing a cognitive frame renewal and the revamping of outdated strategies. The strategy mapping method seems particularly promising for the purpose. It forced entrepreneurs to explain their assumptions about the environment and resources and evaluate their coherence with strategic objectives. Moreover, it induced a comprehensive assessment of the variables relevant to the strategic problem and promoted the recognition of their reciprocal influences. Ultimately, it induced the entrepreneurs to think in new ways about their firms' strategic problems and possibly created grounds for the subsequent translation of the new ideas into practice.

\section{Conclusions}

This paper provides experimental evidence on the impact of the visual representation of strategy and related concepts. We used an original strategy mapping technique and the well-known business model canvas to help entrepreneurs critically review their current strategies and choices. Comparison with a matched control group revealed that strategy visualization induced significant changes in the entrepreneurs' perceptions. Strategy mapping was more effective than the business model canvas in stimulating critical reflection of external discontinuities. We argue that these results are indicative of the utility of visual representations in supporting strategy innovation in rapidly changing environments. To the extent that the revision of consolidated opinions and cognitive models is a credible first step toward the revision of obsolete strategies, we

International Journal of Management and Applied Research, 2016, Vol. 3, No. 1 
conclude that the tools are effective in helping entrepreneurs pursue strategic innovation.

These results have clear practical implications. Recent developments in global competition are exposing entrepreneurs to new, previously inexperienced discontinuities and increasing pressures to modify their strategies and business models. Our findings show that strategy mapping challenges consolidated beliefs and thus constitutes a much needed first step toward strategic renewal. Making implicit assumptions explicit and linking relevant strategy building blocks allows for the identification of potential inadequacies of current strategy and business model and, eventually, promotes the development of new and better ones.

To the best of our knowledge, this is among the first studies to provide empirical evidence of the impact of tools for visualizing strategy and related concepts. We acknowledge, however, that our results are subject to limitations. First, the selection for the experimental and control groups was not random. Since the experiments were time consuming and required two different meetings, we selected the experimental group from among entrepreneurs who were keen to participate. The entrepreneurs were invited to take part in initiatives aimed at helping them with a strategy check-up and innovation. Self-selection is therefore possible, favoring entrepreneurs facing greater changes or uncertainties and therefore more prone to changing their views. Second, we were only able to observe that changes in perceptions on strategic issues occurred, but we do not know if they can be attributed entirely to visual representation. In fact, an in-depth interview with an experienced business analyst could be in itself sufficient to modify participant perceptions. Unfortunately, the tools cannot be tested without personal interaction with an analyst, since the two methods are not selfexplanatory and are certainly difficult for an untrained person without formal education in management to use autonomously. However, the two methods produced slightly different results, albeit statistically significant for just two issues. This result is somewhat reassuring regarding the influence of the visual representation besides the impact of the interview. Finally, the experiments were conducted over a long period and external conditions faced by the entrepreneurs participating at different stages of the study could have changed and could have become more or less uncertain or easy to interpret.

In our experiment we constructed visual representation of strategy and related concepts by means of an in-depth interview with entrepreneurs. Future research could compare the impact of visual representation with that of other kinds of intervention, including in-depth interviews not followed by any other action. Moreover, we documented the modification in entrepreneurs' perceptions induced by strategy visualization, but have no information on longer term consequences of our intervention. Future studies could investigate whether the visual representation of strategy and related concepts is associated with a modification of actual strategies and with which outcomes. 


\section{References}

1. Barr, P. S., Stimpert, J. L. and Huff, A. S. (1992), "Cognitive change, strategic action, and organizational renewal", Strategic Management Journal, Vol. 13 No. 1, pp. 15-36. https://doi.org/10.1002/smj.4250131004

2. Csaszar, F. A., and Levinthal, D. A. (2015), "Mental representation and the discovery of new strategies", Strategic Management Journal, https://doi.org/10.1002/smj.2440

3. Doz, Y. L., and Kosonen, M. (2010), "Embedding strategic agility: A leadership agenda for accelerating business model renewal", Long range planning, Vol. 43, No. 2, pp. 370-382. https://doi.org/10.1016/j.lrp.2009.07.006

4. Eden, C. (1992), "On the nature of cognitive maps", Journal of management studies, Vol. 29, No 3, pp. 261-265. https://doi.org/10.1111/j.14676486.1992.tb00664.x

5. Eppler, M. J. and Platts, K. W. (2009), "Visual strategizing: the systematic use of visualization in the strategic-planning process", Long Range Planning, Vol. 42, No. 1, pp. 42-74. https://doi.org/10.1016/j.1rp.2008.11.005

6. Fiol, C. M., and Huff, A. S. (1992), "Maps for managers: Where are we? Where do we go from here?", Journal of Management Studies, Vol. 29 No 3, pp. 267-285. https://doi.org/10.1111/j.1467-6486.1992.tb00665.x

7. Henderson, B. D. (1979), Henderson on Corporate Strategy, Cambridge: Abt Books.

8. Huff, A. S. (1990), Mapping strategic thought, England: John Wiley \& Sons.

9. Kaplan, R. S., and Norton, D. P. (2000), Having trouble with your strategy? Then map it. Harvard Business School Publishing Corporation.

10. Kaplan, R. S., and Norton, D. P. (2004), Strategy maps: Converting intangible assets into tangible outcomes, Harvard Business Press.

11. Kaplan, R. S., and Norton, D. P. (2006), "How to implement a new strategy without disrupting your organization”, Harvard Business Review, Vol. 84 No 3, pp. 100-109.

12. Kaplan, S. (2008), "Framing contests: Strategy making under uncertainty", Organization Science, Vol. 19, No. 5, pp. 729-752.

https://doi.org/10.1287/orsc.1070.0340

13. Cheng M. M. and Humphreys K. A. (2012), "The Differential Improvement Effects of the Strategy Map and Scorecard Perspectives on Managers' Strategic Judgments", The Accounting Review, Vol. 87, No. 3, pp. 899-924. https://doi.org/10.2308/accr-10212

14. McGee, J. and Thomas, H. (1986), "Strategic groups: theory, research and taxonomy", Strategic Management Journal, Vol. 7, No 2, pp. 141-160. https://doi.org/10.1002/smj.4250070204 
15. Mezias, J., Grinyer, P. and Guth, W. D. (2001), "Changing collective cognition: a process model for strategic change", Long Range Planning, Vol. 34, No. 1, pp. 71-95. https://doi.org/10.1016/S0024-6301(00)00097-2

16. Osterwalder, A. (2004), The business model ontology: A proposition in a design science approach, Ph.D. Thesis, Univeriste de Lausanne

17. Osterwalder, A., and Pigneur, Y. (2010), Business Model Generation: A Handbook For Visionaries, Game Changers, And Challengers, United States of America: John Wiley \& Sons.

18. Porter, M. E. (1980), Competitive Strategy: Techniques for Analyzing Industries and Competitors, New York: Free Press.

19. Simons, R. (1994), "How new top managers use control systems as levers of strategic renewal", Strategic management journal, Vol. 15, No. 3, pp. 169-189. https://doi.org/10.1002/smj.4250150301

20. Teece, D. J. (2010) “Business models, business strategy and innovation”, Long range planning, Vol. 43, No. 2, pp. 172-194.

https://doi.org/10.1016/j.lrp.2009.07.003

21. Trimi, S., and Berbegal-Mirabent, J. (2012), "Business model innovation in entrepreneurship", International Entrepreneurship and Management Journal, Vol. 8, No. 4, pp. 449-465. https://doi.org/10.1007/s11365-012-0234-3

22. Walsh, J. P. (1995), "Managerial and organizational cognition: notes from a trip down memory lane", Organization science, Vol. 6, No. 3, pp. 280-321. https://doi.org/10.1287/orsc.6.3.280 
Annex 1: Questionnaire to assess the perceptions of entrepreneurs (translated from Italian)

Company name:

Participant name:

Role in the company:

Type of business entity:

$\square$ Sole proprietorship

$\square$ Partnership

$\square$ Limited liability company

Net sales (in 1000s of euros):
$\square$ Up to 200
$\square$ From 200 to 1000
$\square$ From 1000 to 5000
$\square$ More than 5000

Number of employees:

$$
\begin{aligned}
& \square \text { Up to } 4 \\
& \square \text { From } 5 \text { to } 10 \\
& \square \text { From } 11 \text { to } 50 \\
& \square \text { More than } 50
\end{aligned}
$$

\begin{tabular}{|c|c|c|c|c|c|}
\hline & $\begin{array}{c}\text { Very } \\
\text { Poor } \\
1\end{array}$ & 2 & 3 & 4 & $\begin{array}{c}\text { Excellent } \\
5\end{array}$ \\
\hline $\begin{array}{l}\text { How good do you think prospects currently are } \\
\text { for your industry sector? }\end{array}$ & o & o & o & $\mathrm{O}$ & o \\
\hline $\begin{array}{l}\text { How good do you think prospects will be for } \\
\text { your industry sector in the future? }\end{array}$ & o & o & o & o & o \\
\hline $\begin{array}{l}\text { How good do you think prospects currently are } \\
\text { for your business? }\end{array}$ & o & $\mathrm{o}$ & o & o & o \\
\hline $\begin{array}{l}\text { How good do you think prospects will be for } \\
\text { your business in the future? }\end{array}$ & o & $\mathrm{O}$ & o & O & o \\
\hline $\begin{array}{l}\text { How do you evaluate your firm's strength in } \\
\text { comparison with your competitors? }\end{array}$ & o & o & o & o & o \\
\hline $\begin{array}{l}\text { How do you evaluate the attractiveness of your } \\
\text { products/services to customers? }\end{array}$ & o & o & o & o & o \\
\hline $\begin{array}{l}\text { How do you evaluate the resources available to } \\
\text { your business? }\end{array}$ & o & o & o & o & o \\
\hline
\end{tabular}

Please rank from 1 (very poor) to 5 (excellent). Please tick one. 